\title{
Um catálogo beneditino em perspectiva bibliográfica: a representação documentária dos livros antigos da Biblioteca do Mosteiro de São Bento em São Paulo, Brasil (séculos XV-XVIII)
}

\author{
A Benedictine catalog in bibliographical perspective: the documentary representation of the old books from the \\ Library of Saint Benedict's Monastery of São Paulo, Brazil (15th-18th century)
}

\author{
Andre Vieira de Freitas Araujo \\ Universidade Federal do Rio de Janeiro. Faculdade de \\ Administração e Ciências Contábeis, Brasil \\ armarius.araujo@gmail.com \\ (iD https://orcid.org/0000-0002-3003-7424
}

\author{
Dina Marques Pereira Araujo \\ Universidade Federal de Minas Gerais. Biblioteca Universitária I \\ Programa de Pós-graduação em Ciência da Informação, Brasil \\ dina.ufmg@gmail.com \\ Dttps://orcid.org/0000-0001-8251-255X
}

\begin{abstract}
Resumo:
O estudo apresenta e discute a concepção, desenvolvimento e consolidação do Catálogo de Livros Antigos (CLA) da Biblioteca do Mosteiro de São Bento de São Paulo (BMSBSP), Brasil. Inicia com a contextualização da BMSBSP, fundada em 1598, e de seus livros antigos (sécs. XV-XVIII), predominantemente representados pelas áreas de Teologia, Direito Canônico, História e Filosofia. A metodologia percorrida é: 1) revisão bibliográfica sobre a temática dos livros antigos, a partir da problematização de seus conceitos e das questóes que se impõem na América Latina e Caribe; 2) construção do CLA, alicerçado no mapeamento, inventário, planejamento e configuração da base de dados e organização da informação de 581 livros antigos da BMSBSP. Um dos resultados deste estudo é a sua contribuição não somente à Biblioteconomia, mas também às investigaçôes de História do Livro, da Leitura e das Bibliotecas no Brasil, na medida em que alargam o exame da presença do livro antigo europeu no Brasil e as perspectivas da biblioteca monástica beneditina em suas dimensões históricas e patrimoniais em terras brasileiras. Concebido no contexto da cultura monástica beneditina, sob o conceito de livro antigo e sob as questões que envolvem a sua representação documentária, o CLA tem um papel não só instrumental, mas também chama a atenção para a importância da materialidade dos textos e de suas formas de organização e de mediação, que podem carregar percursos de longa duração, além de fomentar reflexões mais verticalizadas no âmbito da Bibliografia Histórica.
\end{abstract}

Palavras-chave: Catálogo de livros antigos, Bibliografia histórica, Biblioteca do Mosteiro de São Bento de São Paulo, Livraria de São Bento, Organização da informação, Brasil.

\section{ABSTRACT:}

The study presents and discusses the conception, development and consolidation of the Catalog of Old Books (CLA) from the Library of Saint Benedict's Monastery of São Paulo (BMSBSP), Brazil. It begins with the contextualization of the BMSBSP, founded in 1598, and its old books (15th-18th century), predominantly represented by the areas of Theology, Canon Law, History and Philosophy. The methodology followed is: 1) bibliographical review on the theme of old books, from the problematization of its concepts and the questions that are imposed in Latin America and the Caribbean; 2) construction of the CLA, based on the mapping, inventory, planning and configuration of the database and organization of the information of 581 old books from the BMSBSP. One of the results of this study is its contribution not only to Librarianship, but also to the investigations of the History of Books, Reading and Libraries in Brazil, as they broaden the examination of the presence of the old European book in Brazil and the perspectives of Benedictine monastic library in its historical and heritage dimensions in Brazilian lands. Conceived in the context of Benedictine monastic culture, under the concept of old book and under the questions surrounding its documentary 
representation, the CLA has not only an instrumental role, but also draws attention to the importance of the materiality of the texts and their forms of organization and mediation, which can carry long-term paths, in addition to promoting more vertical reflections within the scope of Historical Bibliography.

KEYWORDS: Catalog of old books, Historical bibliography, Library of Saint Benedict's Monastery of São Paulo, Livraria de São Bento, Information organization, Brasil.

\section{INTRODUÇÃO}

A Biblioteca do Mosteiro de São Bento de São Paulo (BMSBSP) foi fundada em 1598 e sua origem está diretamente ligada à instauração do Mosteiro como projeto de ampliação da Congregação Beneditina Portuguesa no Brasil do séc. XVI.

$\mathrm{Na}$ contemporaneidade, a BMSBSP (Figura 1) pode ser definida por sua pluralidade tipológica: é uma biblioteca particular por pertencer à comunidade monástica beneditina que ainda hoje habita a cidade de São Paulo, é uma biblioteca universitária ligada à Faculdade de São Bento, e também é uma biblioteca especializada.

Figura 1: Biblioteca do Mosteiro de São Bento de São Paulo.

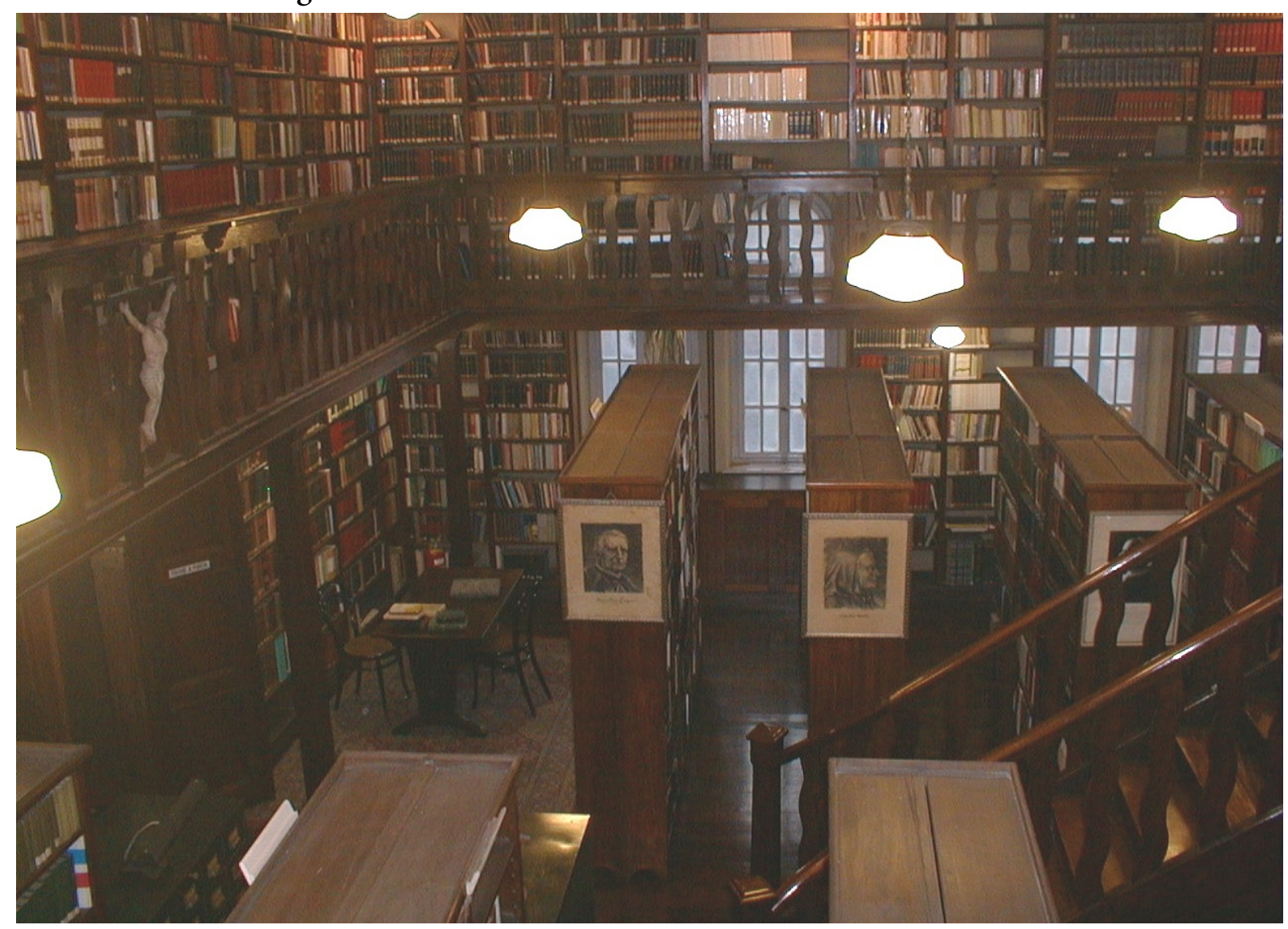

Fonte: Araújo (2008, p. lvi).

Formada por incunábulos (largamente reconhecidos como livros impressos até 1500, inclusive) e obras do séc. XVI ao XVIII, a BMSBSP também possui expressivo acervo dos sécs. XIX, XX e XXI que somam, junto com periódicos e partituras, mais de 100.000 volumes.

Ao manter vestígios de suas antigas características ao longo do tempo, a BMSBSP possui hoje um conjunto de livros antigos, representados predominantemente pelas áreas de Teologia, Direito Canônico, História 
e Filosofia, dos quais alguns possuem evidências ${ }^{1}$ de terem pertencido à Livraria de São Bento, ${ }^{2}$ além de revelarem aspectos da cultura beneditina na São Paulo colonial.

Alicerçado neste cenário, nosso estudo apresenta e discute a concepção, desenvolvimento e consolidação do Catálogo de Livros Antigos (CLA, ${ }^{3}$ sécs. XV-XVIII) da BMSBSP, Brasil.

Do ponto de vista metodológico, o estudo é constituído pelas etapas de: 1) revisão bibliográfica sobre a temática dos livros antigos, a partir da problematização de seus conceitos e das questóes que se impõem na América Latina e Caribe; 2) construção do CLA, alicerçado no mapeamento, inventário, planejamento, configuração da base de dados e organização da informação de 581 livros antigos da BMSBSP. ${ }^{4}$

\section{A DeSignaÇão do LiVRo ANTIGo}

Nos estudos da cultura impressa nos campos da bibliografia, edição, história do livro e das bibliotecas, a denominação "livro antigo" é atribuída aos livros que foram produzidos desde a invenção da imprensa até ao início do séc. XIX - dentre os teóricos referenciais sobre a temática destacamos Martin (1969), McKenzie (1969) e Chartier (1981, 1998). Com base nesses autores, e de um modo geral na História do Livro, há uma tendência ao encerramento cronológico do citado período entre os sécs. XVI e XIX, com possíveis variações. Assim, verificamos que livro antigo é:

[...] a designação atribuída aos livros que foram produzidos desde a invenção da imprensa até o século XIX. De modo mais preciso, e uma vez que os incunábulos constituem uma produção tipográfica à parte, não só pelas suas características próprias, mas também pelo seu tratamento catalográfico, pode dizer-se que o livro antigo abrange as obras impressas desde 1501 até 1800 inclusive. (Faria \& Pericão, 2008, p. 459).

Em relação à essa datação, de início e de término, para delimitação temporal do livro antigo, Martín Abad (2004) alerta para o risco de se universalizar, por uma questão de comodidade, um período que, na realidade, não é coincidente em vários países, quer seja por razões sociais, políticas e/ou culturais.

Fundamentado na bibliografia, Pedraza Gracia, Clemente San Román y Reyes Gómez (2003) indicam que a denominação "livro antigo" engloba materiais bibliográficos variados tanto em sua conformação material como em sua cronologia. Os autores problematizam ainda que há teóricos que não incluem os livros manuscritos na citada denominação, nem mesmo os incunábulos e, após apresentar debates sobre a questão, reforçam para a necessidade da compreensão dos objetos bibliográficos em um sentido amplo. Ainda no campo da bibliografia, sobre a problematização do tema, Martín Abad, González e Lilao Franca (2008) adotam o termo impressos antigos, em uma compreensão ampliada sobre o tema, que contempla o livro antigo e inclusive os incunábulos.

Con la denominación impresos antiguos nos referimos a los libros impresos antiguos, propriamente dichos, pero igualmente a las hojas sueltas y a otras modalidades editoriales formadas em ocasiones por porciones de un único pliego impresso como es el caso de las bulas. La denominación impresos antiguos engloba dos conjuntos tradicionalmente separados [...]: los incunables y los restantes impresos pertenecientes al denominado "período de la imprenta manual" para los que se reserva convencionalmente la denominación de Libros antiguos y em ocasiones de Libros raros o, simplemente, de Raros (Martín Abad, Gonzalez e Lilao Franca, 2008, p. 11, sic.).

Pelo exposto, para a delimitação temporal do livro antigo podemos encontrar variações de datas, de início e de fim, do "antigo regime tipográfico" 5 em países como Inglaterra, França, Espanha e Estados Unidos.

Ao movimentarmos o horizonte de usos da expressão "livro antigo" para os contextos das práticas profissionais em bibliotecas é possível perceber as delimitações temporais e conceituais do termo nas áreas de organização da informação (ordenação, inventariação, arranjo, catalogação), em especial, naquilo que concerne às questões de representação descritiva que perpassam pelas regras biblioteconômico-normativas, por exemplo, os instrumentos para descrição bibliográfica como o International Standard Bibliographic Description for Older Monographic Publications - Antiquarian (ISBD-A) e o Anglo-American Cataloguing 
Rules (AACR2). Nesse universo a expressão "livro antigo" pode apresentar, para além da definição apontada pelos autores citados, apreensóes que dilatam o contexto caracterizado pelo campo da história do livro, e que, por vezes, podem comportar a sinonímia para livro velho, livro usado, livro de sebo, alfarrábio.

$\mathrm{Na}$ biblioteconomia de língua de inglesa, por exemplo, é possível encontrar conceituações sinônimas e/ ou aproximativas do termo "livro antigo" com os termos livro raro, incunábulo, primeiros impressos. Em Cunha e Cavalcanti (2008) podemos identificar os termos "alfarrábio", "livro velho" como equivalentes ou relacionados - inclusive na língua inglesa (ancient book, antique book, early printed book, fine book, rare book). $\mathrm{Na}$ biblioteconomia brasileira, a expressão livro antigo é vista em publicações da área em frequente conexão com às discussões sobre raridade bibliográfica. ${ }^{6}$ Cunha (1987), por exemplo, ao tratar sobre o início da automatização em bibliotecas nacionais em todo o mundo desde a segunda metade do séc. XX, citou os enfoques dados, na época, para a ampliação do conceito de livro antigo. A polissemia do conceito de livro antigo pode apresentar uma série de razões e há que se contextualizar seus usos. Queval (2002), tendo como referência a obra Livre, pouvoirs et société à Paris au XVII ${ }^{\circ}$ siècle (1598-1701), de Henry Jean Martin (1969), afirma que é um equívoco confundir "livro antigo" com as expressões livro velho, livro usado ou livro de sebo.

Além das equivalências, há ainda as ausências do termo em obras de referência do campo da biblioteconomia e da ciência da informação. Em uma busca conceitual do "livro antigo" em língua inglesa, a partir as obras de referência International Encyclopedia of information and library science (Feather \& Sturges, 2003), Encyclopedia of library and information science (Drake, 2005), Encyclopedia oflibrary history (Wiegand \& Davir Jr., 2013), Historical dictionary of librarianship (Quin, 2014), Online dictionary for library and information science (Reitz, 2020), verificamos que as obras não contemplam a expressão livro antigo, nem como verbete ou em forma de remissiva. Há apenas citações para manuscripts, rare book e early printed book. Entretanto, todas as obras fazem referências e conceituam o verbete rare book.

Escapa o objetivo do presente estudo o aprofundamento das questões etimológicas, teóricas e epistemológicas sobre a ausência do verbete "livro antigo" nas obras de referência consultadas. Essa discussão pode seguir em outro momento. Contudo, o esforço de uma possível e necessária aproximação contextual e histórica para abordar sobre a distinção de perspectivas quanto ao livro antigo no campo da história do livro e as obras de referência do campo da biblioteconomia e ciência da informação, as quais não vamos nos dedicar nesse artigo, são importantes.

Dos tensionamentos sobre o conceito de livro antigo apresentados até aqui, surgem as seguintes questões subjacentes: a) o uso do termo livro antigo em bibliotecas está relacionado apenas ao significado europeu no contexto da história do livro?; b) se a adoção do termo "livro antigo" corresponde apenas ao livro europeu, quais significados históricos e culturais, implícitos nessas conceituações, podem obliterar a contextualização do livro antigo na América Latina e Caribe?; c) em outras palavras, quais horizontes de compreensão do livro antigo podem ser considerados, na compreensão do livro antigo na América Latina e Caribe, sem que se promova um apagamento da cultura bibliográfica local?; d) tendo em vista o campo da história do livro na América Latina e Caribe, quais conceitos para livro antigo podem ser identificados, considerando o que nos aproxima e o que nos afasta e ainda os limites temporais e históricos dominantes do livro antigo europeu?; e; e) quais os possíveis modelos de compreensão (teóricos, epistemológicos e técnicos) podem ser considerados diante dos estudos de livros antigos europeus em bibliotecas patrimoniais brasileiras?

Um panorama das compreensões do conceito de livro antigo para a América Latina exige um esforço coordenado de pesquisa, que escapa à capacidade do presente estudo. No Brasil, por exemplo, há, atualmente, um significativo número de acervos privados, religiosos e públicos que contêm vários livros manuscritos e impressos anteriores à história dos primeiros impressos brasileiros. Dessa feita, esses livros denominados como antigos, o são assim pelo exposto, contudo, em tais bibliotecas brasileiras, há livros antigos europeus e livros antigos locais, produzidos nos moldes do antigo regime tipográfico apontados por Chartier (1981), Martin (1969) e McKenzie (1969), mas que correspondem a tempos e contextos diversos daqueles presentes das pesquisas em História do Livro na Europa. Por esse ponto, a "articulação cronológica" 7 do livro antigo na Europa e com América Latina e Caribe exige o estabelecimento de 
modelos de compreensão específicos para cada localidade.

Ainda tendo como abordagem as bibliotecas brasileiras é necessário destacar a presença marcante das bibliotecas formadas por ordens religiosas da igreja católica.

Como exercício de esforço e fortalecimento das construções para compreensão do livro antigo na América Latina, trazemos uma experiência de organização da informação em uma biblioteca monástica beneditina do Brasil - tanto para se apresentar processos e alternativas de inventariação, catalogação, classificação, ordenação e arranjo em bibliotecas patrimoniais, quanto para refletir, com base em uma pílula experimental, sobre as contribuições que as abordagens empíricas podem trazer para o campo da biblioteconomia brasileira, que ainda apresenta poucas reflexões teóricas sobre a questão no contexto dos livros antigos em ambientes eclesiásticos.

\section{O CATÁLOGO BENEDitiNo EM PERSPECTIVA BIBLIOGRÁFiCA: CONCEPÇÃo, DESENVOLVIMENTO E CONSOLIDAÇÃO}

O catálogo aqui discutido, o CLA, é formado, como veremos adiante, por incunábulos e livros antigos. Embora reconheçamos as distinções conceituais entre livros antigos e incunábulos, ambos compõem o Catálogo denominado "Catálogo de Livros Antigos da Biblioteca do Mosteiro de São Bento de São Paulo (sécs. XV-XVIII)". ${ }^{8}$

A organização da informação em bibliotecas com livros antigos é um dos processos mais complexos das atividades bibliográficas e biblioteconômicas, pois exige um trabalho coordenado entre profissionais com conhecimentos da bibliografia, bibliologia, codicologia, paleografia, filologia, história do livro e da edição, idiomas, conhecimentos dos instrumentos técnicos normativos para apoio à descrição bibliográfica - quer seja para inclusão em catálogos, produção de inventários ou de bibliografias -, profundo conhecimento do acervo, além de flexibilidade a possíveis adaptações entre as questões biblioteconômico-normativas e a realidade/fenômeno a ser trabalhado.

Em um país como o Brasil, em que o ensino sobre as práticas de representação descritiva pouco, ou quase nada contemplam o universo do livro antigo, tal prática fica ainda mais suscetível a experimentações locais e à necessidade de contínua troca de experiências. Tal panorama justifica a importância do trabalho teórico-prático aqui proposto e discutido. Outro aspecto que impulsionou o desenvolvimento do CLA é que ele representa a primeira tentativa, na BMSBSP, de se identificar, inventariar e representar, em um único documento, itens dispersos na biblioteca.

Bibliografias especializadas sobre a organização da informação em bibliotecas beneditinas e catálogos beneditinos, ${ }^{9}$ são mínimas e, no caso do Brasil, inexistentes. Deste modo, o trabalho partiu do cruzamento entre reflexão profissional e acadêmica. ${ }^{10}$

O projeto para elaboração do CLA da BMSBSP teve como referência o contato empírico com os livros antigos e estudos aplicados de representação descritiva de livros antigos (Santa Casa..., 1994-1999), de bibliografia (Moraes, 2010) e de bibliografia histórica (McKenzie, 1999), ${ }^{11}$ a partir dos quais foi possível planejar e refletir acerca do CLA e dos problemas bibliográficos que o envolvem.

\subsection{Percurso}

Os processos adotados para a consolidação do CLA da BMSBSP (sécs. XV-XVIII) foram:

1. 1) Mapeamento dos livros antigos: procedemos ao rastreamento/observação, durante seis meses, de todo acervo geral da BMSBSP, ${ }^{12}$ em busca de livros antigos, uma vez que estes não estavam 
separados até então do acervo corrente. Um ponto que devemos ressaltar é a dificuldade e a lentidão necessária pelo fato de se fazer a observação, identificação e registro individual de cada livro antigo somente após a sua localização em um universo de mais de 100.000 volumes. ${ }^{13}$ Após o mapeamento, foram identificadas 581 obras pertencentes aos sécs. XV, XVI, XVII e XVIII.

2. 2) Inventário: primeiramente, todos os títulos foram registrados de forma sumária em um inventário estruturado em planilha do Excel e só depois foram incorporados ao catálogo. Este inventário foi organizado por áreas do conhecimento e dentro de cada área as obras foram arroladas cronologicamente por século e por ano.

3. 3) Planejamento e configuração da base de dados para organização da informação: inicialmente estudamos as características editorais e informacionais dos livros antigos da BMSBSP. Em seguida, passamos à configuração de uma base dados por meio da a) 'definição dos campos'; b) 'definição de planilha de dados'; c) 'definição dos formatos de apresentação dos registros'; e d) 'definição das estratégias de pesquisa'. Para elaboração do catálogo, optamos pelo uso do software Winisis 1.4 (Buxton \& Hopkinson, 2001), que já era adotado no restante do acervo geral da BMSBSP. Para padronização e sistematização dos campos utilizamos o formato Marc 21 (Ferreira, 2000). $\mathrm{Na}$ configuração desta base foram realizadas algumas adaptações dos campos Marc 21, já que os livros antigos possuem informações específicas e que não estão previstas nos sistemas pré-definidos de intercâmbio bibliográfico.

4. 4) Organização da Informação:

4.1 Representações descritiva e temática: as obras foram catalogadas conforme as regras do AACR2 (segunda edição) e procuramos contemplar tanto os aspectos extrínsecos como os aspectos intrínsecos dos itens, de modo a descrever tanto as características editoriais quanto as características específicas dos exemplares. Também foi feita a indexação dos itens, cujo maior desafio foi a extração dos assuntos em função da complexidade linguística, temática e histórica dos itens.

4.2 Ordenação e classificação: também foram realizados os processos de ordenação e classificação, em que se manteve o sistema de arranjo fixo associado às grandes áreas do conhecimento já adotadas historicamente pela BMSBSP.

\subsection{Resultado}

\subsubsection{Inventário}

Conforme já apontado, a representação descritiva e temática e os processos de ordenação e classificação dos 1 ivros foram precedidos pelo inventário que teve como objetivo o levantamento sumário e quantitativo dos 1 ivros antigos da BMSBSP. Para cada livro encontrado foram preenchidos os seguintes campos no inventário ( Figura 2): tombo, local físico, século, ano, autor, título, imprenta, tomo/volume, idioma, MFN (número de registro referente ao sistema utilizado para catalogação automatizada). Ao final de cada área, foram $r$ egistrados o total de livros por séculos e, em seguida, o total por área. 
Figura 2: Extrato do inventário dos livros antigos (sécs. XV-XVIII), área botânica.

\begin{tabular}{|c|c|c|c|c|c|c|c|c|c|}
\hline & & & & & $\begin{array}{l}\text { Abadia de Nossa Senhora da Assunção } \\
\text { Mosteiro de São Bento } \\
\text { Biblioteca-Livraria } \\
\text { ntário dos Livros Antigos (Séculos XV - XVII }\end{array}$ & & & & \\
\hline Tombo & Local & Século & Ano & Autor & Título & Imprenta & Tomo/Volume & Id. & MFN \\
\hline BMLA0020 & $\begin{array}{c}\text { Sala D.Paulo } \\
\text { 1a }\end{array}$ & XVII & 1658 & Gvilielmi Pisonis & $\begin{array}{c}03 \text { - Botânica }(p g, 04) \\
\text { De Indiae Vtrivsque re Natvrali iet Medica Libri } \\
\text { Qvatvordecim, quorvm contenta pagina feqvens exhibet } \\
\text { historiae naturalis \& medicae indiae occidentalis }\end{array}$ & $\begin{array}{l}\text { AMSTELAEDAMI, apud } \\
\text { Ludovicum et Dfanielem } \\
\text { Elzevirios }\end{array}$ & & lat & 4672 \\
\hline BMLA0021 t.1 & 1c & xVIII & 1785 & Vicentii Petagnae & Institutiones Botanicae & Neapoli, Josephi Mariae Porcelli & $\begin{array}{l}\text { Tomus I - de Philosophia } \\
\text { Botanica }\end{array}$ & lat & 3804 \\
\hline BMLA0022 t.2 & 1c & xVIII & 1787 & Vicentii Petagnae & Institutiones Botanicae & Neapoli, Josephi Mariae Porcelli & Tomus II - de Plantis in Specie & lat & 3806 \\
\hline \multicolumn{9}{|c|}{ Total de livros do século XVI } & 0 \\
\hline \multicolumn{9}{|c|}{ Total de livros do século XVII } & 1 \\
\hline \multirow{2}{*}{\multicolumn{9}{|c|}{$\begin{array}{l}\text { Total de livros do século XVIII } \\
\text { Total de livros da área (Botânica) }\end{array}$}} & 2 \\
\hline & & & & & & & & & 3 \\
\hline
\end{tabular}

Fonte: Biblioteca do Mosteiro de São Bento de São Paulo.

Baseado no inventário realizado, obtivemos e registramos o panorama das áreas do conhecimento e a respectiva quantidade de livros antigos (Figura 3).

Figura 3: Gráfico dos livros antigos (sécs. XV-XVIII) por área.

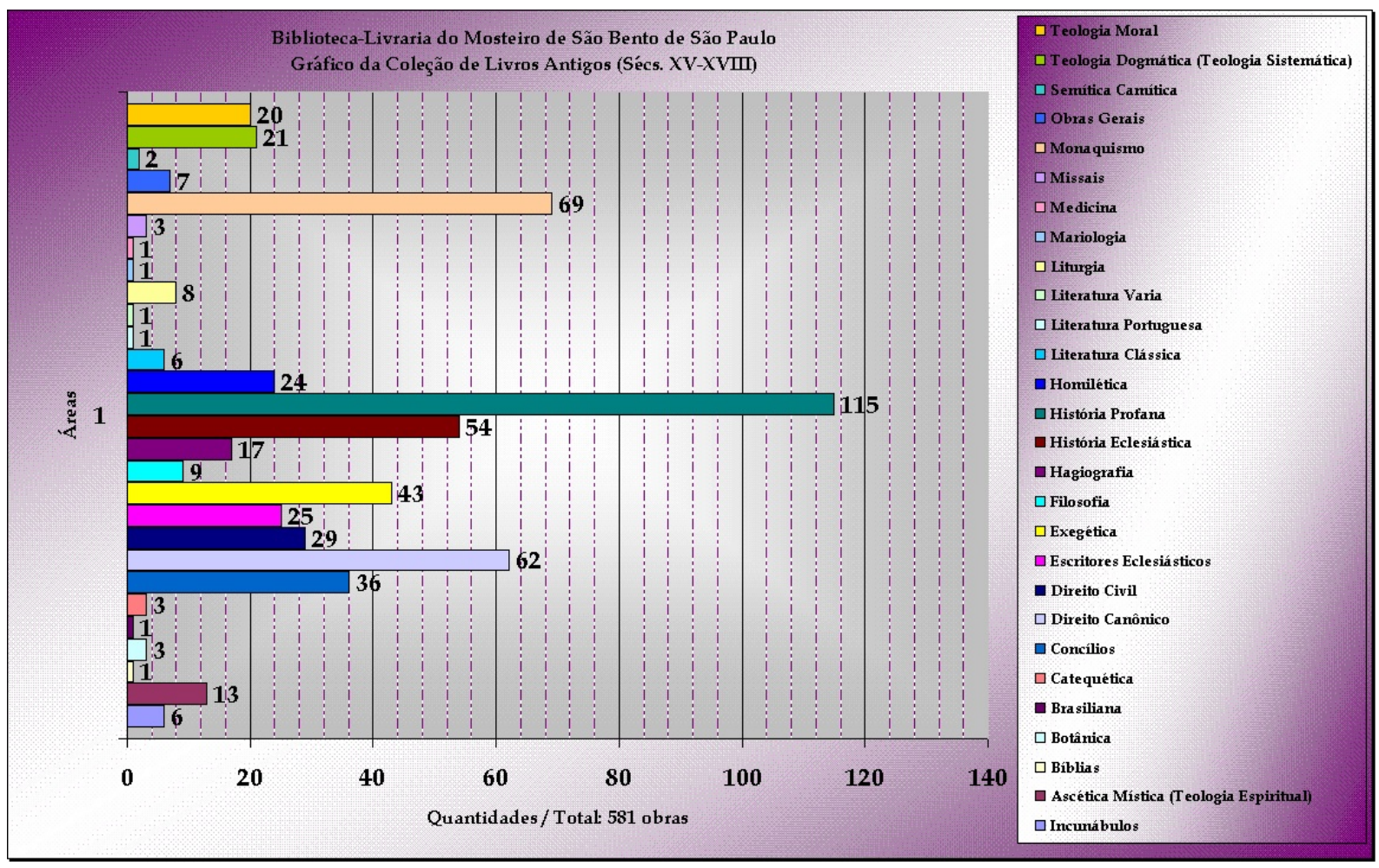

Fonte: Araújo (2008, p. lxv).

Abaixo (Figura 4) visualizamos as áreas e as respectivas quantidades por séculos e totais. Foi justamente a partir do inventário que obtivemos dados mais precisos dos livros antigos do ponto de vista temáticoquantitativo. 
Figura 4: Relatório quantitativo dos livros antigos (sécs. XV-XVIII) em ordem alfabética.

\begin{tabular}{|c|c|c|c|c|c|c|c|}
\hline \multirow{2}{*}{$\mathbf{N}^{0}$} & \multirow{2}{*}{ Área } & \multicolumn{4}{|c|}{ Séculos } & \multirow{2}{*}{ Total } & \multirow{2}{*}{$\%$} \\
\hline & & XV & $\mathrm{XVI}$ & XVII & XVIII & & \\
\hline 0 & Incunábulos & 6 & 0 & 0 & 0 & 6 & $1,03 \%$ \\
\hline 1 & $\begin{array}{l}\text { Ascética Mística (Teologia } \\
\text { Espiritual) }\end{array}$ & 0 & 2 & 1 & 10 & 13 & $2,24 \%$ \\
\hline 2 & Bíblias & 0 & 0 & 1 & 0 & 1 & $0,17 \%$ \\
\hline 3 & Botânica & 0 & 0 & 1 & 2 & 3 & $0,52 \%$ \\
\hline 4 & Brasiliana & 0 & 0 & 1 & 0 & 1 & $0,17 \%$ \\
\hline 5 & Catequética & 0 & 0 & 0 & 3 & 3 & $0,52 \%$ \\
\hline 6 & Concílios & 0 & 0 & 36 & 0 & 36 & $6,20 \%$ \\
\hline 7 & Direito Canônico & 0 & 2 & 5 & 55 & 62 & $10,67 \%$ \\
\hline 8 & Direito Civil & 0 & 0 & 8 & 21 & 29 & $4,99 \%$ \\
\hline 9 & Escritores Eclesiásticos & 0 & 14 & 6 & 5 & 25 & $4,30 \%$ \\
\hline 10 & Exegética & 0 & 1 & 11 & 31 & 43 & $7,40 \%$ \\
\hline 11 & Filosofia & 0 & 0 & 3 & 6 & 9 & $1,55 \%$ \\
\hline 12 & Hagiografia & 0 & 0 & 2 & 15 & 17 & $2,93 \%$ \\
\hline 13 & História Eclesiástica & 0 & 0 & 5 & 49 & 54 & $9,29 \%$ \\
\hline 14 & História Profana & 0 & 0 & 3 & 112 & 115 & $19,79 \%$ \\
\hline 15 & Homilética & 0 & 2 & 13 & 9 & 24 & $4,13 \%$ \\
\hline 16 & Literatura Clássica & 0 & 1 & 1 & 4 & 6 & $1,03 \%$ \\
\hline 17 & Literatura Portuguesa & 0 & 0 & 1 & 0 & 1 & $0,17 \%$ \\
\hline 18 & Literatura Varia & 0 & 1 & 0 & 0 & 1 & $0,17 \%$ \\
\hline 19 & Liturgia & 0 & 0 & 2 & 6 & 8 & $1,38 \%$ \\
\hline 20 & Mariologia & 0 & 0 & 1 & 0 & 1 & $0,17 \%$ \\
\hline 21 & Medicina & 0 & 0 & 0 & 1 & 1 & $0,17 \%$ \\
\hline 22 & Missais & 0 & 0 & 0 & 3 & 3 & $0,52 \%$ \\
\hline 23 & Monaquismo & 0 & 0 & 11 & 58 & 69 & $11,88 \%$ \\
\hline 24 & Obras Gerais & 0 & 0 & 0 & 7 & 7 & $1,20 \%$ \\
\hline 25 & Sem ítica Camítica & 0 & 0 & 1 & 1 & 2 & $0,34 \%$ \\
\hline 26 & $\begin{array}{l}\text { Teologia Dogmática (Teologia } \\
\text { Sistemática) }\end{array}$ & 0 & 0 & 0 & 21 & 21 & $3,61 \%$ \\
\hline 27 & Teologia Moral & 0 & 0 & 0 & 20 & 20 & $3,44 \%$ \\
\hline & Total Geral & 6 & 23 & 113 & 439 & 581 & $100,00 \%$ \\
\hline
\end{tabular}

Fonte: Araújo (2008, p. lix). 


\subsubsection{Do inventário ao catálogo}

Concomitantemente ao desenvolvimento do inventário, foi planejado o CLA da BMSBSP (sécs. XVXVIII), segundo o percurso já mencionado.

Após o planejamento e pré-testes, demos início à organização da informação dos livros antigos. Para a constituição do CLA, os 581 livros identificados na fase de mapeamento passaram pelas etapas de tombamento, ordenação, classificação, representação descritiva e indexação em ambiente automatizado.

Na versão impressa, o CLA da BMSBSP (sécs. XV-XVIII) está organizado da seguinte forma:

$1^{\circ}$ : as obras estão agrupadas alfabeticamente (seja pela inicial do sobrenome do autor ou do título) dentro das áreas do conhecimento que também estão dispostas alfabeticamente; ${ }^{14}$

2: em cada área do conhecimento, o pesquisador encontra informações descritivas e temáticas sobre os livros registrados. Os seguintes campos constituem a versão impressa do catálogo: autor, título, edição, imprenta (composta pelo local, casa publicadora/editora, ano e informações do impressor/impressão), número de páginas, ano, século da obra, nota geral, nota de conteúdo (contendo em alguns casos a biografia do autor ou mesmo dados históricos sobre a obra), marca Da Livraria São de Bento (que é marca de propriedade manuscrita da antiga Biblioteca do Mosteiro), assunto, assunto (termo livre), assunto (nome próprio), idioma (indicado por sua abreviatura), área do conhecimento e número de tombo.

Em Araújo (2008, p. xl) é possível visualizar um exemplo de descrição de um livro antigo, correspondente à versão impressa do catálogo (Figura 5). 
Figura 5: Catálogo de livros antigos - Versão impressa

Registro da obra tombada sob o número BMLA0436.

Literatura varia15
GESNERO, Conrado. BIBLIOTHECA VNIVERFALIS: fue Catalogus omnium
fcriptorum locupletiffimus, in tribus linguis, Latina, Graeca, \& Hebraica: extantium \& non
extantiu, ueterum \& recentiorum in hunc ufqdiem, doctorum \& indoctorum,
publicatorum \& in Bibliothecis latentium. Opus nouum, \& no Bibliothecis tantum publicis
priuatisue inftituendis neceffarium, fed ftudiofis omnibus cuiufcumque artis aut fcientiae
ad ftudia melius formanda utiliffimum: authore CONRADO GESNERO Tigurino doctore
medico. Tigvri: Apvd Christophorvm, MDXLV. 1262 p. ${ }^{16}$
Ano: 1545 -- Séc: XVI.
Nota Geral: Exemplar com encadernação original em madeira e couro, em ótimo
estado de conservação, faltando apenas os fechos em metal da capa. A numeração
encontra-se apenas nas páginas ímpares (atuais), ou seja, a impressão está
numerada até $631{ }^{17}$
Nota de Conteúdo: Bibliografia Latina, Grega e Hebraica, com inúmeras referências.
Conrad Gesner (1516-1564), também conhecido como von Gesner, foi médico,
bibliotecário e naturalista suíço. Apesar de pouco conhecido fora dos meios
acadêmicos, Conrad Gesner foi um dos maiores intelectuais da história da ciência,
tendo publicado, em vida, mais de 70 livros, sobre os assuntos mais variados, como
linguística, medicina, teologia, botânica, zoologia, paleontologia e mineralogia. Deixou,
ainda, mais 20 outros livros na forma de manuscrito.
Marca da Livraria São Bento: Não.
Assunto (s): BIBLIOGRAFIAS; BIBLIOTECAS; CATALOGOS; LITERATURA
CLASSICA.
Assunto (s)[TL]: BIBLIOGRAFIA HISTORICA.
Idioma: lat.
Area do conhecimento: Literatura Varia.
Número de Tombo: BMLA0436.

Fonte: Araújo (2008, p. xl).

A versão automatizada do catálogo (que contém informações mais completas que a versão impressa) está acessível na Base de Dados Benedictus - mantida localmente pela BMSBSP. Embora disponibilizado para consulta local e em um sistema já superado (Winisis), o Catálogo pode perfeitamente ser migrado para outro ambiente.

No que toca à estrutura da base de dados, foram definidos campos referentes ao Formato Marc 21, de modo a estabelecer um padrão de descrição estruturado em campos e subcampos (Figura 6): 
Figura 6: Catálogo de livros antigos. Visão parcial da tela de edição de dados do registro (MFN) 4707.

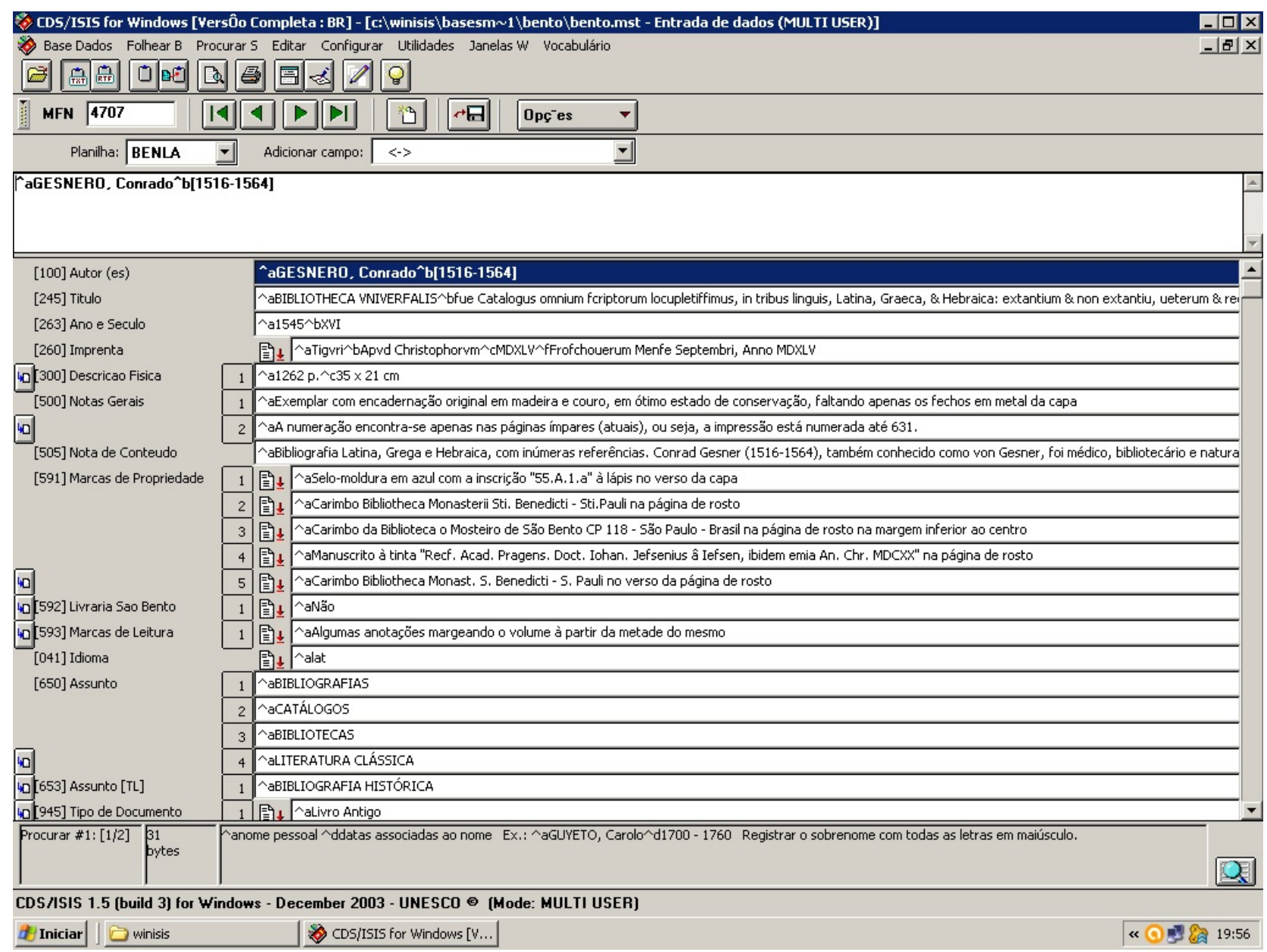

Fonte: Base de Dados Benedictus - Biblioteca do Mosteiro de São Bento de São Paulo.

O desafio na etapa de desenho e de arquitetura da base esteve justamente na definição de campos, já que a configuração de uma base de livros antigos requer a implementação de campos e subcampos que não seguem exatamente o mesmo modelo para acervos correntes/contemporâneos.

Um caso emblemático desta questão está no campo imprenta (etiqueta Marc 21 260). Normalmente os três subcampos principais são "a" (local), "b" (casa publicadora) e "c" (ano). No CLA também adotamos subcampo "f" 18 (impressor/impressão), cujo preenchimento deveria ser feito com informações referentes ao impressor e à permissão concedida para publicação da obra, seja real ou eclesiástica. Tal informação é inerente ao universo dos livros antigos e advém do conhecimento prévio da história do livro. Destacamos aqui a necessidade do bibliotecário de conhecer as disciplinas instrumentais que fundamentam o processo de descrição de um documento gráfico (codicologia, bibliografia, paleografia), estudar sobre os instrumentos normativos ${ }^{19}$ e o software que serão usados para a construção do catálogo e, especificamente, superar o desafio dos metadados dos softwares, que escassamente correspondem às metodologias de descrição indicadas pelas disciplinas instrumentais citadas acima.

Por fim, temos a tela de visualização do usuário (Figuras 7 e 8): 
Figura 7: Catálogo de livros antigos. Visão parcial da tela de visualização do registro (MFN) 4707.

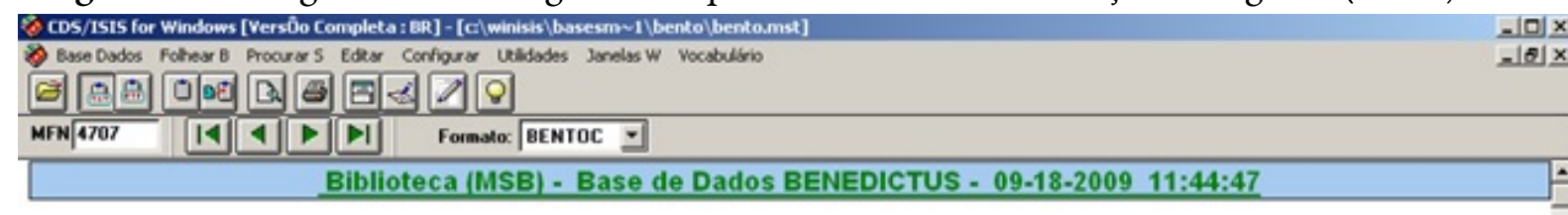

\section{Autor(es): \\ Titulo:}

\section{Ano e Século:}

Imprenta:

Descricao Fisica:

Notas Gerais: Nota de Conteudo: $\quad$ ou seja, a impressão esta numerada até 631.

GESNERO, Conrado

BIBLIOTHECA VNIVERFALIS : fue Catalogus omnium fcriptorum locupletiffimus, in tribus linguis, Latina, Graeca, \& Hebraica: extantium \& non extantiu, ueterum \& recentiorum in hunc ufqdiem, doctorum \& indoctorum, publicatorum \& in Bibliothecis latentium. Opus nouum, \& no Bibliothecis tantum publicis priuatisue inftituendis neceffarium, fed ftudiofis omnibus cuiufcumque artis aut fcientiae ad ftudia melius formanda utiliffimum: authore CONRADO GESNERO Tigurino doctore medico / Conrado Gesnero (Conrad Gesner)

1545 -- Séc. XVI

Tigvii : Apvd Christophorvm, MDXLV, Frofchouerum Menfe Septembri, Anno MDXLV

1262 p. : $35 \times 21 \mathrm{~cm}$

Exemplar com encadernação original em madeira e couro, em otimo estado de conservação, faltando apenas os fechos em metal da capa. A numeração encontra-se apenas nas páginas impares (atuais).

Nota de Conteudo: Bibliografia Latina, Grega e Hebraica, com inúmeras referências. Conrad Gesner (1516-1564),

tambem conhecido como von Gesner, foi médico, bibliotecario e naturalista suiço. Apesar de pouco conhecido fora dos meios acadêmicos. Conrad Gesner foi um dos maiores intelectuais da historia da ciência, tendo publicado, em vida, mais de 70 livros, sobre os assuntos mais variados, como lingüistica, medicina, teologia, botảnica, zoologia, paleontologia e mineralogia. Deixou, ainda, mais 20 outros livros na forma de manuscrito.

Marcas Propriedade:Selo-moldura em azul com a inscriçáo "55-A.1.a" à lápis no verso da capa. Carimbo Bibliotheca Monasterii Sti. Benedicti - Sti.Pauli na pagina de rosto. Carimbo da Biblioteca o Mosteiro de São Bento CP 118 - São Paulo - Brasil na pagina de rosto na margem inferior ao centro. Manuscrito à tinta "Recf. Acad. Pragens. Doct. lohan. Jefsenius â lefsen, ibidem emia An. Chr. MDCXX" na pagina de rosto. Carimbo Bibliotheca Monast. S. Benedicti - S. Pauli no verso da pagina de rosto

Marca Livr. S. Bento: Năo

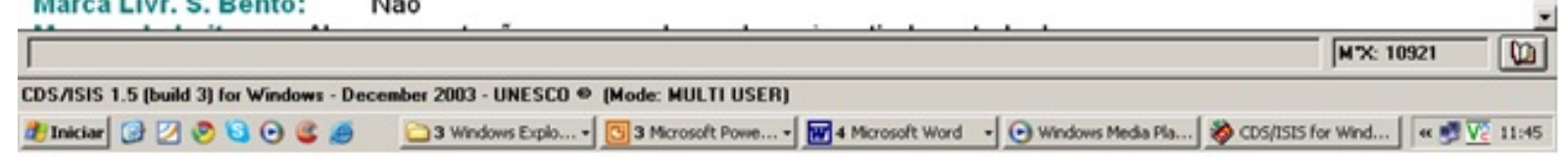

Fonte: Base de Dados Benedictus - Biblioteca do Mosteiro de São Bento de São Paulo. 
Figura 8: Catálogo de livros antigos. Visão parcial da tela de visualização do registro (MFN) 4707 (cont.).

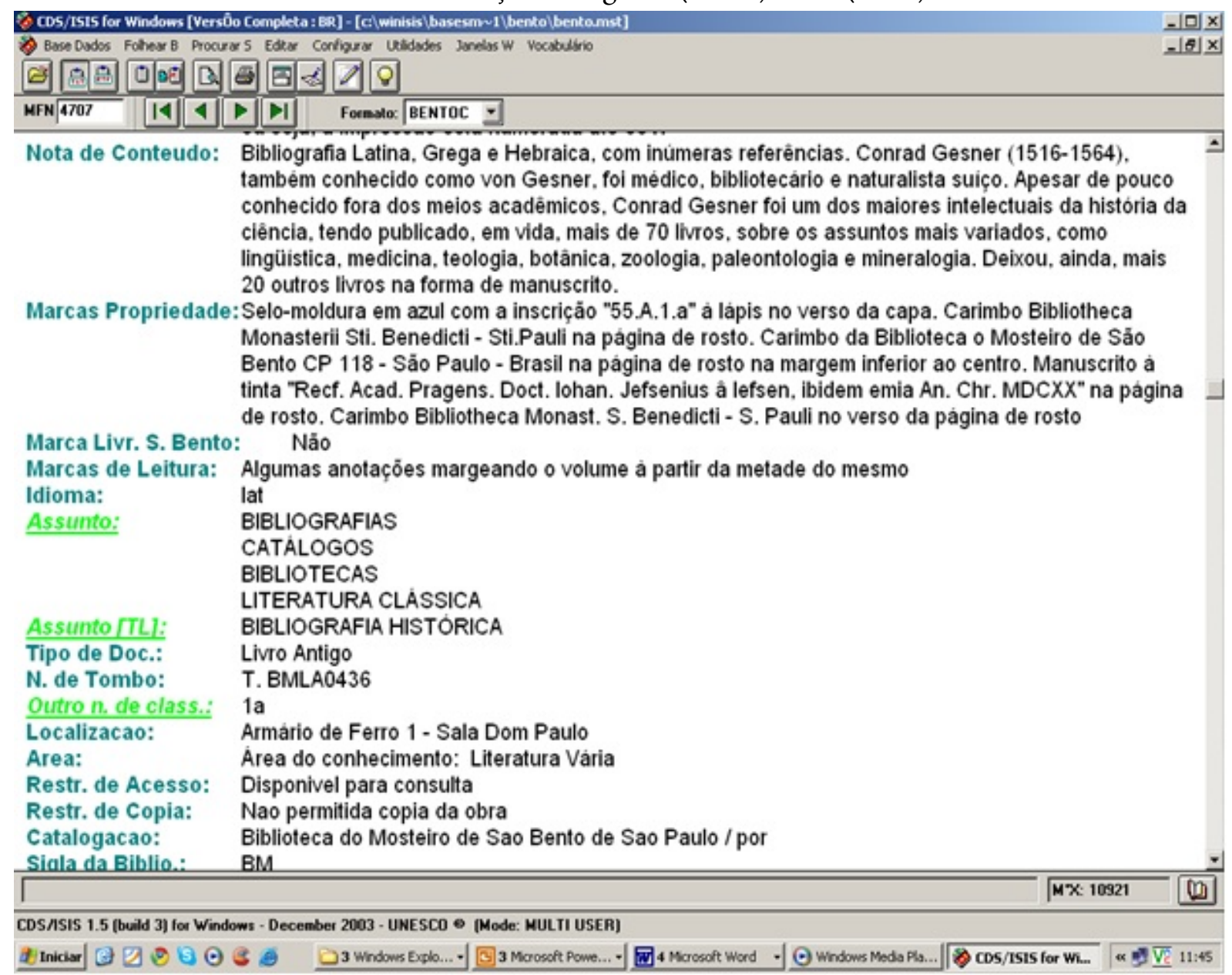

Fonte: Base de Dados Benedictus - Biblioteca do Mosteiro de São Bento de São Paulo.

Baseado na tela de visualização do registro (MFN) 4707 (Figuras 7 e 8), destacamos outros exemplos emblemáticos para o tratamento específico aos livros antigos: a configuração do campo "Marca da livraria de São Bento" (Marc 592), para a indicação ou não da existência da marca de propriedade da instituição (no caso, da Livraria de São Bento) e o campo "Marcas de leitura" (Marc 593), para registro das possíveis marcas de leitura do exemplar descrito.

A título de nota, as marcas de propriedade, ${ }^{20}$ identificadas em alguns dos livros foram diversas, tais como: “Da Livra de Sbto" (Figura 9); "Da Livra do Mosteiro de S. Bto de S. Paulo"; "Da Livra. de S. Bento" e "Biblioteca do Mosteiro de São Bento", registradas, sobretudo, no frontispício ou ao final das obras. Este levantamento só foi possível por meio da análise minuciosa item a item ao longo do processo de representação descritiva. 
Figura 9: Marca de propriedade Da Livra de Sbto.

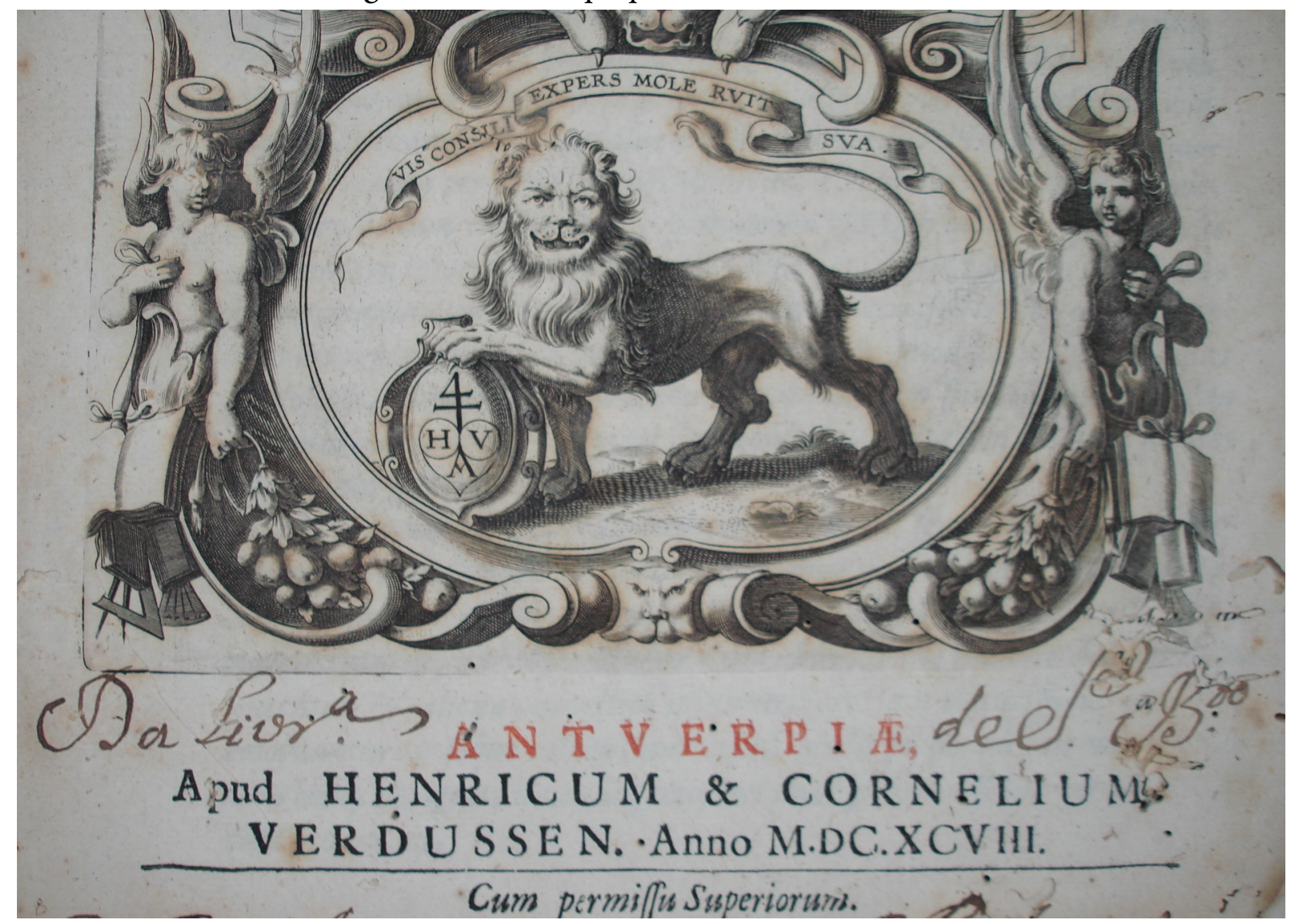

Observa-se a marca de propriedade manuscrita na obra Cursus philosophicus universus... (1698), de Thomas Compton-Carleton (1591-1666). Fonte: Livros Antigos da Biblioteca do Mosteiro de São Bento de São Paulo.

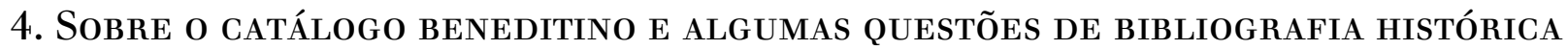

A construção do CLA da BMSBSP apontou, a partir da observação quantitativa do acervo, um fenômeno bastante significativo à história do livro e discutido por Villalta (2002): no séc. XVI existiam poucos livros, em relação aos séculos vindouros, sendo que o número de proprietários de livros era restrito e, ainda, cada um deles tinha uma quantia reduzida de volumes, em grande parte referentes à religião; já no séc. XVII, a situação de posse de livros praticamente não foi alterada em relação ao século anterior e no séc. XVIII assistiu-se uma mudança tanto na posse de livros como na formação de bibliotecas. Portanto, observamos que as características da Livraria de São Bento acompanharam a tônica de composição das bibliotecas do séc. XVI a o XVIII.

Ainda que não seja o foco deste estudo, a prática de leitura e a sua historia é um aspecto que está diretamente vinculado ao CLA, uma vez que este instrumento nos permite a identificação de títulos que possivelmente fizeram parte do cotidiano de leitura no Mosteiro da São Paulo colonial. Estes títulos podem nos responder, por exemplo, algumas das questões cruciais em estudos de história da leitura que é 'o que se lề, tendo a vantagem de associarem 'o que' com 'quem' da leitura. ${ }^{21}$

Compreendemos que a experiência bibliográfica e cultural dos monges pode ser deduzida, então, não só com base na seleção e na composição do conjunto de livros antigos através dos séculos, mas também com base dos próprios vestígios encontrados nesses livros. Articuladas aos elementos da bibliografia histórica, estas mesmas questóes estão, portanto, relacionadas ao suporte, confirmando o quanto a materialidade define as dinâmicas de uso e de apropriação dos textos ao longo do tempo. 
D. F. McKenzie (1999) lembra com vigor o valor simbólico dos signos e das materialidades. Para ele, as diferentes formas impõem diferentes modos de lidar com o texto e a informação, portanto, a forma material do texto determina seu significado.

Outro aspecto coligado às questões de bibliografa histórica é que no percurso de construção do CLA da BMSBSP, embora um conjunto de informações tenha sido concebido pela leitura documentária de cada um dos itens, consideramos também dados de ordenação e de classificação que já pertenciam aos livros antigos, ou seja, dados referentes a sua possível ordenação histórica.

A respeito da ordem bibliográfica na Livraria de São Bento, Araújo (2012, p. 16) afirma que “[...] os procedimentos de organização levaram a novas formas de conhecimento, assim como estes levaram a novos modos de organizar a Livraria já que seus livros deveriam ser classificados conforme as articulações intelectuais da época”.

Nesse sentido, o exercício de bibliografia histórica que realizamos atravessou e ao mesmo tempo dilatou a dimensão instrumental e funcional do catálogo, na medida em que corresponde a um percurso histórico de concepção e reflexão de e sobre os produtos documentários que demarcaram e demarcam a cultura monástica beneditina. Tal percepção é confirmada quando endereçamos o CLA às Constituições Monásticas (Constitutiones..., 1629), que determinavam a necessidade de elaboração de um catálogo ou inventário na biblioteca, e ao Plano e Regulamentos dos Estudos para a Congregação de S. Bento de Portugal (Plano..., MDCCLXXXIX), que determinava a presença de um bibliotecário responsável pelo índice na Biblioteca (Livraria).

Podemos afirmar que a concepção do CLA da BMSBSP representa, ${ }^{22}$ com efeito, a manutenção de algumas das recomendaçóes quanto à necessidade de elaboração de um catálogo ou inventário da biblioteca. Ou seja, representa um exercício bibliográfico na esteira da longa duração histórica.

\section{CONSIDERAÇÕES FINAIS}

O percurso de concepção e consolidação do Catálogo que aqui apresentamos não pretendeu ser um trabalho definitivo. É fruto do mapeamento, levantamento, registro e organização, ${ }^{23}$ dos livros antigos que hoje compóem parte do acervo geral da BMSBSP.

O CLA da BMSBSP segue critérios contemporâneos de organização da informação associados à natureza histórica dos livros. Também dá pistas para o estudo parcial da constituição do acervo, dos fragmentos das práticas de leituras e do sentido de ordem da Biblioteca do Mosteiro, além de fomentar pesquisas nas diferentes áreas do conhecimento que o contornam.

A importância deste estudo está na sua dimensão documentária por agora possibilitar uma investigação mais sistematizada e conceitual dos livros antigos, como por exemplo, análise acerca de sua materialidade, fundamentada na bibliografia material, ou mesmo o desenvolvimento de estudos mais apurados sobre as obras à luz de sua produção, impressão até a circulação em meios livrescos, ${ }^{24}$ dentre outras possibilidades. Outras ações merecerem ser implementadas ao CLA, a saber: a) pesquisar fontes e repertórios de raridade e indicar notas bibliográficas; b) migrar os dados do Winisis para outros sistemas; c) identificar exemplares de mesma edição em outros catálogos e bibliotecas digitais online para referenciar; d) digitalizar títulos que ainda não estão disponíveis em formato digital; e e) desenvolver ações para produção de um catálogo coletivo beneditino no Brasil.

Ao refletir sobre as bibliotecas patrimoniais na América Latina, nos referimos aqui às práticas biblioteconômicas adotadas a partir do séc. XX é possível identificar que em processos de gestão, a atribuição de livro(s) antigo(s) pode fazer referência, por vezes, aos livros e/ou coleções que fundaram a biblioteca de determinada instituição. Pensando em termos de datação, os livros que receberão tal nominação poderão ser tanto dos sécs. XV ao XVIII, quanto dos sécs. XIX e XX. E todo esse conjunto documental acabaria por 
receber uma identificação de antigo, não necessariamente, por contextualizações históricas com a cultura escrita de um modo amplo, mas porque o antigo, nesse cenário, tem como referência o que é antigo para a história local daquela biblioteca.

Por este ângulo, o presente estudo buscou demonstrar a importância de historicizar e contextualizar os termos, para não cairmos nas "armadilhas das palavras" (Chartier, 1998). Não contextualizar os termos, ao analisar os documentos gráficos em bibliotecas na América Latina pode, assim, configurar-se em um modo de esquecimento das multiplicidades de culturais gráficas presentes em acervos patrimoniais. Pensar os acervos em termos de amplitudes culturais, conexões interculturais da produção e circulação do livro de modo global sem apagamento do local é uma das formas de adentrar no universo da cultura gráfica em territórios fixos, mas não rígidos de interpretação da história do livro e das bibliotecas. A bibliografia, notadamente a bibliografia histórica, enquanto teoria, episteme e técnica, pode ser a chave de leitura e elo entre as culturas do livro nos sécs. XV-XVIII, na Europa, e suas passagens e permanências na América Latina.

O estudo aqui estabelecido pretendeu contribuir às investigações sobre as atividades bibliográficas, em uma tentativa de ampliar e mesmo deslocar uma abordagem prática e funcional para uma reflexão teóricometodológica, de natureza histórica, dos instrumentos e produtos da organização da informação, em perspectiva bibliográfica.

Assim mesmo, este estudo também pode contribuir não somente à biblioteconomia, mas também às investigações de história do livro, da leitura e das bibliotecas no Brasil, na medida em que alargam o exame da presença do livro antigo europeu no Brasil e as perspectivas da biblioteca monástica beneditina em suas dimensões históricas e patrimoniais em terras brasileiras.

Concebido no contexto da cultura monástica beneditina, sob o conceito de livro antigo e sob as questões que envolvem a sua representação documentária, o CLA da BMSBSP tem um papel não só instrumental, mas também chama a atenção para a importância da materialidade dos textos e de suas formas de organização e de medição, que podem carregar percursos de longa duração histórica, além de fomentar reflexões mais verticalizadas no âmbito da bibliografia histórica.

\section{REFERÊNCIAS}

Anglo-American Cataloguing Rules(AACR2) - Código de catalogação anglo-americano - (1983-1985). (2 Vol.). (2a ed.) São Paulo: Federação Brasileira de Associações de Bibliotecários.

Araújo, A. (2001). Bibliotecas monásticas beneditinas:suas características na contemporaneidade (Monografia de Trabalho de Conclusão de Curso de Biblioteconomia), Faculdade de Filosofia e Ciências, UNESP, Marília/SP.

Araújo, A. (2008). Dos livros e da leitura no claustro: elementos de história monástica, de história cultural e de bibliografia histórica para estudo da Biblioteca-Livraria do Mosteiro de São Bento de São Paulo (sécs. XVI-XVIII). (Dissertação e mestrado em História Social), Faculdade de Filosofia, Letras e Ciências Humanas, USP, São Paulo. Recuperado de http://www.teses.usp.br/teses/disponiveis/8/8138/tde-10022009-124405/

Araújo, A. (2012). Ordo Librorum: a ordem dos livros na Livraria de São Bento de São Paulo (sécs. XVI-XVIII). Em Encontro Nacional de Pesquisa em Ciência da Informação, Rio de Janeiro, Brasil. Recuperado de http://www. eventosecongressos.com.br/metodo/enancib2012/arearestrita/pdfs/19553.pdf

Araújo, D. M. P. \& Reis, A. S. (2017). Bibliografias setecentistas e os conceitos de livro raro. Perspectivas em ciência da informação, 22, 168-184. https://doi.org/10.1590/1981-5344/3239

Araújo, D. M. P.; Reis, A. S. e Silveira, F. J. N. (2018). Bibliofilia, bibliografias e a construção do sistema axiológico da raridade. Informação \& informação, 23(2), 38-57. https://doi.org/10.5433/1981-8920.2018v23n2p38

Association of College and Research Libraries (2007). Descriptive cataloging of rare materials (books) - DCRM. Washington, D.C.: Cataloging Distribution Service.

Buxton, A., \& Hopkinson, A. (2001). The CDS/ISIS for Windows handbook. Paris: UNESCO/CI. 
Campos, F. (2015). Para se achar facilmente o que se busca: bibliotecas, catálogos e leitores no ambiente religioso (século XVIII). Casal de Cambra: Caleidoscópio.

Chartier, R. (1981). L’Ancien Régime typographique: réflexions sur quelques travaux recentes. Annales ESC, 36(2), 191-209.

Chartier, R. (1998). A ordem dos livros: Leitores, autores e bibliotecas na Europa entre os séculos XIV e XVIII. 2a ed. Brasília: Ed. UnB.

Chartier, R. (2002). Bibliografia e história cultural. In R. Chartier, À beira da falésia: a história entre certezas e inquietude. Porto Alegre: Ed. UFRGS.

Chartier, R. (2003). Leituras populares. In R. Chartier, Formas e sentido, cultura escrita. Entre distinção e apropriação. Campinas: ALB: Mercado de Letras.

Chartier, R. (2012). Ancien Régime typographique. In P. Fouché, P. Péchon e P. Shuwer (Dir.) Dictionnaire encyclopédique du livre (Vol. 1, pp. 92-94). Paris: Éditions du Cercle de la Librarie.

Constitutiones Monachorum Nigrogum Ordinis. (1629). S.P. Benedict Regnorum Portugalliae. Conimbricae: Apud Didacum Gomes de Loureyro.

Cunha, L. F. F. (1987). A política do livro antigo no exterior e no brasil. BIBLOS - revista do Instituto de Ciências Humanas e da Informação, 2, 17-40. Recuperado de http://hdl.handle.net/20.500.11959/brapci/22614

Cunha, M. B. e Cavalcanti, C. R. (2008). Dicionário de biblioteconomia e arquivologia. Brasília: Briquet de Lemos/ Livros.

Darnton, R. (1992). Historia da leitura. In P. Burke (Org.), A escrita da história (pp. 199-236). São Paulo: Editora UNESP.

Drake, M. A. (Ed.). (2005). Encyclopedia of library and information Science. 2a ed. London; New York; Singapore: Taylor \& Francis.

Faria, M. I.; Pericão, M. G. (2008). Dicionário do livro: da escrita ao livro eletrônico. São Paulo: EDUSP.

Feather, J. \& Sturges, P. (2003). International encyclopedia of information and library Science. $2^{\mathrm{a}} \mathrm{ed}$. New York; London: Routledge.

Ferreira, M. M. (2000). MARC 21: Formato condensado para dados bibliográficos (2 Vol.). Marília (SP): UNESP; Exlibris.

Giurgevich, L. \& Leitão, H. (2016). Clavis bibliothecarum: catálogos e inventários de livrarias de instituições religiosas em Portugal até 1834. Lisboa: Secretariado Nacional para os Bens Culturais da Igreja.

Martin, H. J. (1969). Livre, pouvoirs et société à Paris au XVII ' siècle (1598-1701). Genève: Droz.

Martín Abad, J. (2004). Los libros impresos antiguos. Valladolid: Universidad de Valladolid, Secretariado de Publicaciones e Intercamnio Editorial.

Martín Abad, J.; González, M. B. e Lilao Franca, Ó. (2008). La descripción de impressos antiguos. análisis y aplicación de la $\operatorname{ISBD}(A)$. Madrid: Arco/Libros.

McKenzie, D. F. (1969). Printers in the mind: some notes on bibliography. Papers of the Bibliographical Society of the University of Virginia, 22, 1-75.

McKenzie, D. F. (1999). Bibliography and the sociology of texts. Cambridge: Cambridge University Press.

McKitterick, D. (2018). The invention of rare books: private interest and public memory, 1600-1840. Cambridge: Cambridge University Press.

Moraes, R. B. (2010). Bibliographia brasiliana: livros raros sobre o Brasil publicados desde 1504 até 1900 e obras de autores brasileiros do periodo colonial. (2 vols.). São Paulo: EDUSP, FAPESP.

Pedraza Gracia, M. J.; Clemente San Román, Y. y Reyes Gómez, F. (2003). El libro antiguo. Madrid: Síntesis.

Plano e Regulamentos dos Estudos para a Congregação de S. Bento de Portugal (MDCCLXXXI, Primeira Parte). Lisboa: Na Régia Oficina Tipográfica.

Queval, É. (2002). Anciens livres. In P. Fouché, P. Péchon e P. Shuwer (Dirs.). Dictionnaire encyclopédique du livre (Vol. 1, p. 94). Paris: Éditions du Cercle de la Librarie. 
Quin, M. E. (2014). Historical dictionary of librarianship. Lanham, Boulder, New York, Toronto, Plymouth, UK: Rowman \& Littlefield.

Reitz, J. M. (2020). Online dictionary for library and information science. Recuperado de https://products.abc-clio.co $\mathrm{m} /$ ODLIS/odlis_r.aspx

Santa Casa da Misericórdia de Lisboa. (1994-1999). Arquivo / Biblioteca. Catálogo das obras impressas no século XV, XVI, XVII e XVIII. (4 vols.). Lisboa: Santa Casa de Misericórdia de Lisboa.

Varela-Orol, C. (2016). El concepto de libro raro en el siglo XVIII: la recepción de la obra de David Clément en España. Revista general de información y documentación, 26(2), 631-650.

Villalta, L. C. (2002). Os leitores e os usos dos livros na América Portuguesa. In M. Abreu (Org.). Leitura, história e história da leitura. Campinas: Mercado das Letras: Associação de leitura do Brasil; São Paulo: Fapesp.

Wiegand, W. A. \& Davir J. D. G. (Ed.). (2013) Encyclopedia of library history. New York, London: Routledge.

\section{Notas}

1 Possuem marcas de propriedade e marcas de leitura.

2 Termo utilizado para denominar a antiga Biblioteca do Mosteiro de São Bento de São Paulo, na época da Província Beneditina (1592-1827).

3 O CLA foi concebido em função de motivações profissionais-biblioteconômicas (organização e salvaguarda do patrimônio bibliográfico da BMSBSP) e de pesquisa de um dos autores deste artigo. Em relação a este aspecto, a CLA tornou-se uma das fontes para o desenvolvimento da investigação que resultou na dissertação "Dos livros e da leitura no Claustro: elementos de história monástica, de história cultural e de bibliografia histórica para estudo da BibliotecaLivraria do Mosteiro de São Bento de São Paulo (sécs. XVI-XVIII)”. Cf. Araújo (2008).

4 Neste trabalho, questões como formação e desenvolvimento de coleções, preservação e conservação, acesso e digitalização não serão abordadas, embora todas sejam relevantes ao debate sobre os livros antigos. A ideia aqui é discutir a organização da informação em bibliotecas patrimoniais, especificamente no que se referente aos processos de arranjo, ordenação, inventariação e descrição de livros antigos.

5 "Os três séculos e meio que separam a invenção da imprensa e a composição de tipos móveis na década de 1450, da primeira industrialização da impressão do livro, no início do século XIX, pode ser designado como um 'Antigo Regime tipográfico". (Chartier, 2012, v.1, p. 92-94).

6 A raridade é uma temática que não vamos abordar no presente artigo. Para discussões sobre a invenção da raridade ver: Varela-Orol (2016), Araújo e Reis (2017); Araújo, Reis e Silveira (2018); Mckitterick (2018).

7 Chartier (2003, p. 150).

8 O CLA da BMSBSP foi inserido, parcialmente, na dissertação de Araújo (2008). Neste mesmo estudo também é possível verificar aspectos histórico-culturais sobre a constituição do acervo.

9 Não podemos deixar de mencionar a monumental e rigorosa investigação de Giurgevich \& Leitão (2016) que mapeou e identificou 901 catálogos, inventários e listas de livrarias de mosteiros (incluindo beneditinos), conventos e outras instituições religiosas em Portugal até 1834. Também destacamos o estudo de Campos (2015) acerca de livros e livrarias de ordens religiosas portuguesas no séc. XVIII. A partir da análise de catálogos, inventários e índices de livrarias, Campos explora a estrutura organizacional das bibliotecas, a ordem dos livros e dos saberes e a sua relação com os leitores. $\mathrm{O}$ estudo se desenvolve a partir da análise quantitativa dos espólios bibliográficos, considerando, ainda, suas marcas de proveniência e seus usos sociais.

10 O interesse pelo estudo da cultura beneditina de um dos autores deste estudo teve início em 2001. Cf. Araújo (2001).

11 Entendida neste contexto como a mudança de relações entre os livros e sociedades que os produziram e os utilizaram, mas também como a abordagem histórica de sistemas bibliográficos para organização da informação.

12 A BMSBSP fica na clausura e seu acervo é fechado ao usuário externo, o que restringe a livre circulação em seu interior.

13 Em um mapa conceitual-físico que chamamos de "Croqui" registramos a posição física dos livros antigos conforme a sua localização original, para não impor apagamentos às histórias dos arranjos e das ordenações dos livros da BMSBSP. Para visualização do "Croqui", ver Araújo (2008).

14 As áreas do conhecimento que foram adotadas no catálogo são exatamente as mesmas áreas utilizadas na Biblioteca e que "encabeçam/sinalizam" cada uma das estantes/prateleiras onde estão os livros antigos. Não identificamos o critério exato para a escolha destes termos para as áreas estabelecidas, mas sabemos que têm sido adotadas pelo menos desde o séc. XIX. Por outro lado, é interessante observarmos que essas mesmas áreas são recorrentes nas bibliotecas beneditinas 
como um todo, mesmo antes do séc. XIX. Tal constatação foi feita e discutida por Araújo (2012), a partir do método indiciário, em estudo específico sobre a "antiga” ordem dos livros antigos na Livraria de Sáo Bento (sécs. XVI-XVIII).

15 Denominação da área do conhecimento que encabeça a estante onde está localizado o livro.

16 Onde se lê: GESNERO, Conrado. BIBLIOTHECA VNIVERFALIS: fue Catalogus omnium fcriptorum locupletiffimus, in tribus linguis, Latina, Graeca, \& Hebraica: extantium \& non extantiu, ueterum \& recentiorum in hunc ufqdiem, doctorum \& indoctorum, publicatorum \& in Bibliothecis latentium. Opus nouum, \& no Bibliothecis tantum publicis priuatisue inftituendis neceffarium, fed ftudiofis omnibus cuiufcumque artis aut fcientiae ad ftudia melius formanda utiliffimum: authore CONRADO GESNERO Tigurino doctore medico. Tigvri: Apvd Christophorvm, MDXLV. 1262 p. Considere: GESNER, Conrad. Bibliotheca Universalis, sive Catalogus omnium scriptorum locupletissimus, in tribus linguis, Latina, Graeca, \& Hebraica: extantium \& non extantium, veterum \& recentiorum in hunc usque diem, doctorum \& indoctorum, publicatorum \& in Bibliothecis latentium. Opus novum \& non Bibliothecis tantum publicis privatisue instituendis necessarium, sed studiosis omnibus cuiuscunque artis aut scientiae ad studia melius formanda utilissimum: authore CONRADO GESNERO Tigurino doctore medico. Tiguri: apud Christophorum Froschouerum Mense Septembri, Anno MDXLV. 1262 p. Estas grafias também devem ser consideradas em suas ocorrências nas Figuras 6 e 7. Contudo, mantivemos no corpo do texto e também nas imagens a grafia adotada no registro bibliográfico original do Winisis.

17 A encadernação em livros antigos é um paratexto que demonstra os usos e as práticas ao longo da história do livro. A descrição de encadernações em catálogos de bibliotecas patrimoniais possibilita a identificação de uma variedade de modelos técnicos e estéticos praticados pelos atores da cultura gráfica, além de indicar, por vezes, se colecionadores ou instituições fizeram reencadernações. Tal descrição deve ser estruturada de modo a possibilitar a construção de um inventário fundamentado em referenciais da história da encadernação. Enquanto recomendação para a descrição de encadernações uma proposta adotada, por exemplo, no Acervo de Obras Raras da Universidade Federal de Minas Gerais, é a de seguir os seguintes passos: A) com base em referencial teórico e/ou tesauro: 1) indicar tipologia da encadernação, seguida de datação; 2) descrever elementos técnicos e estéticos; 3) descrever materiais; 4) fazer transcrição fac-símile dos elementos decorativos e gráficos. B) controlar os termos e datas do item " 1 " a partir do uso de tesauros e/ou do controle da base de dados da instituição. O exemplar indicado nas Figuras 5, 6 e 7 possui encadernação com materiais e modelos técnicos-estéticos que a caracterizam como uma encadernação tradicional do séc. XVI (na qual ainda podemos verificar os vestígios de algumas práticas das encadernações do período medieval), como, por exemplo, as pastas produzidas a partir de placas de madeira, revestimento em couro com elementos de metal nos quatro ângulos e nos fechos. As folhas de guarda do exemplar são com papel branco e o corpo do livro é composto por papel de fibra longa e foi costurado sobre nervos de pele dupla (possivelmente pergaminho) e os cabeceados tecidos com linha sobre fio de pergaminho. Em outra ocasião vamos abordar, especificamente, sobre as encadernações de Gesner em exemplares presentes nas bibliotecas patrimoniais brasileiras. Quando da data de conclusão das descrições no CLA a pesquisa sobre a citada encadernação do exemplar ainda estava em fase inicial.

18 A indicação de tal subcampo, na base local, justificou-se por ser vinculado ao campo devido (Imprenta) para indicar informações do impressor e a permissão de impressão e, ainda, pelo benefício de indicar tal informação para o consulente da base de dados.

19 Enquanto prática aplicada à experiência com o CLA, destacamos as orientações normativas (AACR2, DCRM) e as orientações do formato para descrição (MARC 21) para a área de descrição "Publicação", especificamente, em relação às indicações de privilégios, autorizações e permissões para impressão: a) AACR2: a regra 2.7B9 orienta que quando as informações forem retiradas de locais que não a página de rosto deve-se redigir uma nota especificando a fonte de informação. b) DCRM: a regra 7B8 orienta que deve ser feita descrição específica para "Publicação" na área de "Notas". c) MARC 21: o campo (Imprenta) 260 não prevê subcampos para indicar permissão de impressão. De acordo com sua estrutura, o campo para essa descrição seria em notas $5 \mathrm{XX}$, no qual não há um campo para nossa necessidade de descrição. O campo para mais próximo seria 550 (chamado de "Publicação"), contudo ele se aplica às publicações seriadas. Consideramos aqui que tanto as normativas quanto as ferramentas de descrição disponíveis na atualidade estão fortemente direcionadas para as características dos impressos modernos e não para as dos impressos antigos.

20 Considerando a diversidade de marcas de propriedade encontradas nos livros antigos, estamos diante de um conjunto que potencialmente pode e deve ser investigado à luz dos estudos de proveniência bibliográfica.

21 Robert Darnton (1992) chega a afirmar que um catálogo de uma biblioteca particular pode servir como perfil de um leitor, pois tem a vantagem de unir o "o que" com o "quem" da leitura. Uma importante contribuição do historiador norte-americano é apontar fontes complementares que podem colaborar para a realização de estudos sobre o livro e o hábito da leitura.

22 Catálogos são fontes elementares para se estudar historicamente bibliotecas, já que uma parcela importante da história bibliográfica se dá pela análise e compressão da lógica das listas, inventários e catálogos de bibliotecas.

23 A organização realizada foi de sistematização dos dados das obras e não física, já que as obras - mesmo após inclusão no catálogo - ainda permanecem no seu local de origem, ou seja, nas áreas e nas estantes já determinadas na biblioteca. 
Palabra Clave (La Plata), octubre 2021-marzo 2022, vol. 11, n 1, e136. ISSN $1853-9912$

24 Este processo só pode ser compreendido pela "[...] descrição e análise das características físicas de exemplares conservados da edição (ou das edições) do texto considerado”. Cf. Chartier (2002). 